grateful to the Distillers' Company, Ltd., for a gift of glutathione, and to Miss Stewart for care of the hydra; one of us (E. E. C.) is in receipt of a Thornton bursary.

Nuffield Laboratory of Ophthalmology,

E. E. CLIFF"

S. G. W.ALEX

University of Oxford. July 14.

${ }^{1}$ Loomis, W. F., Ann. N.Y. Acad. Sci., 62, 209 (1955).

${ }^{2}$ Waley, S. G., Biochem. J., 84, 715 (1956).

${ }^{3}$ Waley, S. G., Biochem. J., 67, 172 (1957).

- Waley S. G., Biochem. J., 68, 189 (1958).

${ }^{5}$ Loomis, W. F., and Lenhoff, H. M., J. Exp. Zool., 132, 555 (1956)

'Kermack, W. O., and Matheson, N. A., Biochem. J., 65, 48 (1957).

'Waley, S. G., Biochem. Soc. Symposium (in the press).

\section{Adrenal Activity in Subjects with Complete Transverse Lesions of the Spinal Cord}

Human subjects with complete transverse lesions of the upper thoracic and cervical spinal cords show some features of hypoactivity of the adrenal medulla and of the adrenal cortex : the concentration of adrenaline in the peripheral plasma ${ }^{1}$ and the excretion of 17-ketogenic steroids in the urine ${ }^{2}$ are both significantly lower than normal.

Since eosinophilia is commonly found in conditions of adrenal insufficiency it was of some interest to measure the number of eosinophils in the blood of patients with complete transverse lesions of the upper thoracic and cervical cord, that is above the fifth thoracic vertebra (T.5), and to compare them with the values found in patients with cord lesions below T.5. This latter group of patients showed no features of adrenal hypoactivity. Eosinophil counts were carried out by the method of Pilot ${ }^{3}$.
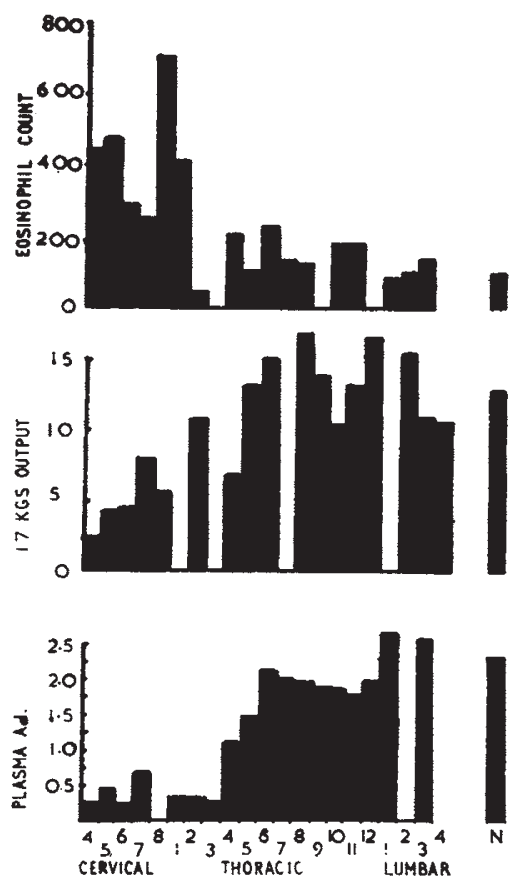

LEVEL OF CORD LESION

Fig. 1. Mean values of eosinophil count in cclls per mm. ${ }^{3}$ (top) 17-ketogenic steroid excretion in mgm. per $24 \mathrm{hr}$. (middle) and plasma adrenaline in $\mu g m$. (bottom). The columns marked ' $N$ ' show the mean results of groups of normal control subjects
Thirteen out of twenty-one patients with complete spinal cord lesions above T.5 showed some degree of eosinophilia with counts above 300 per $\mathrm{mm} .{ }^{3}$; twentythree patients with lesions complete below T.5 were all normal.

The accompanying figure shows the mean values for plasma adrenaline, 17-ketogenic steroid excretion and circulating eosinophils in patients with complete transverse lesions of the spinal cord at levels from the fourth cervical to the fourth lumbar vertebra.

Patients with high cord lesions tend to have high eosinophil counts, low values for the plasma adrenaline and low excretions of 17-ketogenic steroids; patients with lesions of the lower thoracic and lumbar cords show normal values.

Long 4 has developed the idea that adrenaline, which is assumed to be released during stress, stimulates the secretion of adrenocorticotrophic hormone. He found that the adrenal cholesterol and ascorbic acid fell under these circumstances and also after adrenaline infusion.

Our investigations were carried out on fit subjects with spinal cord lesions of long standing who were not under stress. It is interesting that the association between the activity of the adrenal cortex, as measured by the eosinophil count and the excretion of 17-ketogenic steroids, and the output of adrenaline still appears to hold even in circumstances of subnormal adrenaline output.

National Spinal Injuries Centre,

R. ROBINSON

Stoke Mandeville Hospital, Aylesbury.

Dept. of Physiology, King's College,

University of London.

${ }^{1}$ Munro, A. F, and Robinson, R., J. Physiol., 141, 4P (1958)

2 Robinson, R., Nature, 181, 484 (1958).

${ }^{3}$ Pilot, Brit. Med. J., 4741 (1951).

"Long, C. N. H., in "Symposium on Stress" (C.S. Army Medical Service Graduate School, Washington, 1951).

\section{Acetylcholine in Mammalian Neuromuscular Transmission}

After reviewing experimental results described in the literature, Acheson ${ }^{1}$ came to the conclusion in 1948 that the amount of acetylcholine liberated by a single impulse at a presynaptic nerve terminal in muscle and sympathetic ganglia is probably of the order of $1.5 \times 10^{-16} \mathrm{gm}$. (10-18 moles). He pointed out the large discrepancy between this quantity and the relatively large amounts $\left(3 \times 10^{-14}\right.$ moles $)$ hitherto found necessary for excitation when applied directly to the muscle. This discrepancy has been much reduced in recent years by the electrophoretic application of acetylcholine from micropipettes ${ }^{3,7}$, and spikes have been produced in frog muscle fibres by this method with as little as $5.5 \times 10^{-16}$ moles $^{7}$. However, there still remained a substantial difference, and most of the potentials obtained by this method have not been strictly comparable with end-plate potentials elicited by nerve stimulation since they have a much slower time-course. For example, the quickest potential published by del Castillo and Katz ${ }^{3}$ rose to its maximum in 13 msec. These authors concluded that much faster potentials, and even greater sensitivity to acetylcholine, would be expected in the case of nervous release of acetylcholine, where the diffusion distance is less than $I \mu$; in their 